\title{
Progressive Unilateral Damage of the Entorhinal Cortex Enhances Synaptic Efficacy of the Crossed Entorhinal Afferent to Dentate Granule Cells
}

\author{
Julio J. Ramirez, Ketan R. Bulsara, Sandra C. Moore, Karl Ruch, and William Abrams \\ Laboratory of Behavioral Neuroscience, Department of Psychology, Davidson College, Davidson, North Carolina 28036
}

Progressive injury to the mammalian CNS often reduces the severity of lesion-induced deficits or spares the behavior from deficits altogether. The mechanism(s) underlying this behavioral sparing is not clearly understood, but axonal sprouting is a likely candidate. To test this possibility, unilateral, two-stage (progressive) lesions of the entorhinal cortex, which are known to accelerate sprouting by the crossed temporodentate pathway and spare spatial memory function, were made in rats. We examined the changes in synaptic efficacy (as measured by the amplitude and slope of evoked population EPSPs) of the crossed temporodentate projection after either one-stage or progressive unilateral lesions of the entorhinal area. Whereas the synaptic efficacy of the one-stage group did not differ significantly from the control group at 4,6 , or $8 \mathrm{~d}$ after the lesion, the synaptic efficacy of the crossed temporodentate pathway in the progressive lesion group significantly increased above the control values as early as $4 \mathrm{~d}$ after the lesion and remained stable thereafter. Axonal sprouting thus may provide a mechanism by which to account for behavioral sparing after progressive brain damage.

Key words: crossed temporodentate pathway; entorhinal cortex; functional reorganization; hippocampus; neuroplasticity; sprouting
Numerous studies over the last 25 years have documented anatomical, cellular, and molecular lesion-induced alterations that may provide the basis for recovery of function after CNS insults. These alterations have been observed in sensory and motor systems, limbic structures, cortical structures, and the spinal cord (Freund et al., 1997). The hippocampal formation is of particular interest in this context because of its key contribution to learning and memory (Squire, 1992). In rats, a unilateral lesion of the entorhinal cortex (EC) denervates the outer molecular layer of the dentate gyrus of the hippocampal formation by as much as 90\% (Steward and Vinsant, 1983). Within 7-14 d after a lesion, several remaining afferents [including the crossed temporodentate projection (CTD), the septodentate pathway, and the commissural and associational inputs] sprout and reinnervate the denervated molecular layer (for review, see Ramirez, 1997).

Despite an abundance of observations demonstrating the ubiquitous nature of CNS sprouting, the behavioral significance of lesion-induced sprouting remains uncertain. Investigations of the hippocampal formation, however, have shown that rats exhibit spatial memory deficits from which they recover $\sim 8-12$ d after unilateral entorhinal lesions (Loesche and Steward, 1977; Reeves and Smith, 1987), a time course comparable with that of hippocampal sprouting. Crossed temporodentate sprouting has been implicated in the recovery of spatial memory function after

\footnotetext{
Received July 27, 1999; revised Sept. 22, 1999; accepted Sept. 22, 1999.

This work was supported by National Science Foundation Grant IBN9722829 and National Institute of Neurological Disorders and Stroke Grant NS31740 to J.J.R. We are grateful to Drs. Richard Tomasulo and Edward Palmer for helpful comments on this manuscript.

Correspondence should be addressed to Dr. Julio J. Ramirez, Laboratory of Behavioral Neuroscience, Department of Psychology, Davidson College, Davidson, NC 28036. E-mail: juramirez@davidson.edu.

Copyright (C) 1999 Society for Neuroscience $\quad 0270-6474 / 99 / 190001-\bullet \$ 05.00 / 0$
}

unilateral EC lesions for three reasons: first, it originates in the same cell layer as the injured contralateral entorhinal input to dentate gyrus (Steward, 1976); second, it exhibits many of the electrophysiological characteristics of the original pathway (e.g., habituation, paired-pulse potentiation, and long-term potentiation) (Steward et al., 1976b; Harris et al., 1978; Reeves and Steward, 1986); and third, transection of the sprouted CTD reinstates the spatial memory impairment (Loesche and Steward, 1977; Ramirez et al., 1996).

The objective of the present experiment was to determine electrophysiologically whether unilateral progressive EC lesions enhance CTD synaptic efficacy. Using the progressive lesion technique (Scheff et al., 1977), we previously have shown that two-stage (progressive) lesions of the EC in one hemisphere accelerate CTD sprouting and spare spatial memory function in rats (Ramirez et al., 1996). Because anatomical demonstration of terminal proliferation does not indicate the establishment of functional synapses, the demonstration of electrophysiological activity of sprouted pathways is an important parameter to bridge the structural and behavioral changes occurring in response to CNS lesions. Here we reasoned that if reactive synaptogenesis is

This article is published in The Journal of Neuroscience, Rapid Communications Section, which publishes brief, peerreviewed papers online, not in print. Rapid Communications are posted online approximately one month earlier than they would appear if printed. They are listed in the Table of Contents of the next open issue of JNeurosci. Cite this article as: JNeurosci, 1999, 19:RC42 (1-6). The publication date is the date of posting online at www.jneurosci.org.

http://www.jneurosci.org/cgi/content/full/3698 
accelerated by progressive lesions, substantial increases in synaptic efficacy should be evident as early as $4 \mathrm{~d}$ postlesion (dpl), i.e., the time point at which we had previously observed enhanced terminal proliferation in response to a progressive EC lesion.

\section{MATERIALS AND METHODS}

Subjects and experimental design. Male, Sprague Dawley rats (325-375 gm; $n=68$ ) were randomly assigned to one of four treatment conditions: (1) intact control $(n=5)$, (2) priming lesion only (lateral-most EC; $4 \mathrm{dpl}$, $n=5 ; 6 \mathrm{dpl}, n=9 ; 8 \mathrm{dpl}, n=6)$; (3) one-stage unilateral EC lesion (4 dpl, $n=9 ; 6 \mathrm{dpl}, n=5 ; 8 \mathrm{dpl}, n=6)$; (4) progressive lesion, consisting of a priming lesion (lateral-most EC) followed 6 d later [i.e., the interoperation interval (IOI) we used previously (Ramirez et al., 1996)] by a secondary lesion (remaining lateral and medial EC; $4 \mathrm{dpl}, n=7 ; 6 \mathrm{dpl}$, $n=5 ; 8 \mathrm{dpl}, n=11)$. With the exception of the control group, each group was subjected to electrophysiological procedures at 4,6 , or $8 \mathrm{~d}$ after either the IOI or the one-stage lesion. The priming group was included to determine whether the priming lesion itself initiated a sprouting response; therefore, recordings were made relative to the time at which the secondary lesions would have been made (i.e., 10, 12, or $14 \mathrm{~d}$ after the priming lesion).

Surgery. The rats were injected intraperitoneally with $0.1 \mathrm{ml}$ of atropine sulfate followed by sodium pentobarbital (Nembutal, $50 \mathrm{mg} / \mathrm{kg}$ ) anesthetic. Electrolytic EC lesions were made at the following coordinates: $1.5 \mathrm{~mm}$ anterior to transverse sinus, 2, 4, and $6 \mathrm{~mm}$ ventral from dura, and 3, 4, and $5 \mathrm{~mm}$ lateral to the sagittal sinus (cf. Loesche and Steward, 1977). The CTD and the perforant path share the outer two-thirds of the molecular layer of the dentate gyrus (Hjorth-Simonsen and Jeune, 1972; Goldowitz et al., 1975; Wyss, 1981; Davis et al., 1988; Steward et al., 1988). Consistent with our previous investigation (Ramirez et al., 1996), progressive lesions consisted of priming lesions of the lateral-most EC ( $5 \mathrm{~mm}$ lateral to sagittal sinus), followed by lesions of the remaining lateral and medial EC after the IOI.

Electrophysiological procedures. We amplified, displayed, recorded, and analyzed evoked potentials after EC stimulation, according to procedures described earlier (Steward et al., 1973, 1976a; Reeves and Steward, 1986). Rats were anesthetized with chloralose-urethane $(55 \mathrm{mg} / \mathrm{kg}$ and $0.3 \mathrm{gm} / \mathrm{kg}$, respectively) and supplemental urethane doses as needed. After removal of the skull overlying the hippocampus and EC, a twistedwire, bipolar electrode was inserted into the EC contralateral to the damaged EC (8.1 mm posterior to bregma, $4.2 \mathrm{~mm}$ lateral to the sagittal sinus, and initially $2.5 \mathrm{~mm}$ ventral to dura). A recording electrode $(0.9 \%$ $\mathrm{NaCl}$-filled glass micropipette; impedance, 1-3 $\mathrm{M} \Omega$ ) was placed over the dorsal hippocampus at $3.2 \mathrm{~mm}$ posterior to bregma and $1.5 \mathrm{~mm}$ lateral to the sagittal sinus. The response recorded by an extracellular recording electrode in the dentate hilus after contralateral angular bundle stimulation is characterized by a positivity with a latency of response of $\sim 2.5$ msec (Lomø, 1971; Steward et al., 1973). The depth of the electrode was determined by maximal positivity in the dentate hilus to entorhinal stimulation (test pulses, $5.0 \mathrm{~mA} ; 300 \mu \mathrm{sec}$ duration). A monosynaptic connection between the EC and the dentate gyrus was verified by stimulating the contralateral perforant path at a frequency of $100 \mathrm{~Hz}$ (cf. Lom $\varnothing, 1971)$. Whereas the population EPSP of a polysynaptic connection cannot follow a stimulus train of this frequency, the population EPSP of a monosynaptic pathway can (Lomø, 1971). We also mapped the response to verify whether the waveform exhibits an extracellular negativity at a recording site just dorsal to the hilar response, i.e., in the vicinity of the dentate molecular layer (Lomø, 1971; Steward et al., 1973). We again ascertained the monosynaptic nature of the pathway by stimulating the contralateral perforant path at $100 \mathrm{~Hz}$. After our verification procedures, a response was maximized and isolated. The field potentials were evoked at a frequency of $0.1 \mathrm{~Hz}$ (monophasic, square-wave pulses; width, $300 \mu \mathrm{sec}$ ) with a World Precision Instruments (Sarasota, FL) digital stimulator and amplified with an Axoprobe electrometer (Axon Instruments, Foster City, CA) and Tektronix (Wilsonville, OR) amplifier. Filter bandpass was set at $0.1 \mathrm{~Hz}$ to $10 \mathrm{kHz}$. Evoked potentials were digitized and averaged on an IBM personal computer with Digiscope Evoked Potential software. Two forms of data were collected after stimulus artifact onset: (1) the maximum evoked amplitude and (2) the maximum slope. The amplitude and slope of the extracellular evoked potentials were taken as indices of synaptic efficacy because they reflect the ability of the CTD to drive the target granule cells and correlate well with intracellular indices of granule cell excitation (Lomø, 1971; Steward et al., 1973, 1976a; White et al., 1976). Each sample was obtained by averaging five sweeps. The baseline for our measurements was taken immediately before the onset of stimulus artifact.

Histological procedures. At the termination of the experiments, the rats were overdosed with Nembutal (sodium pentobarbital, $100 \mathrm{mg} / \mathrm{kg}$ ) and were perfused with $10 \%$ neutral buffered formalin. The brains were frozen-sectioned horizontally. The sections were stained with cresyl violet acetate for evaluation of the lesion extent.

\section{RESULTS \\ Electrophysiology}

Statistical analyses (ANOVAs and Dunnett a priori comparisons) were performed on the maximum amplitude of the evoked response and on the maximum slope of the response at 4, 6, and $8 \mathrm{~d}$ after the IOI. The evoked responses observed in the progressive lesion group, unlike any other group, were significantly greater than control values as early as $4 \mathrm{dpl}$ (i.e., after IOI; Dunnett $a$ priori comparison, $p=0.01$; Omnibus $F$ test: $F_{(3,22)}=4.57$; $p<$ 0.05; Fig. 1). Moreover, this increase was evident at the 6 and $8 \mathrm{~d}$ time points $(6 \mathrm{dpl}$ : Dunnett a priori comparison, $p<0.002$; Omnibus $F$ test, $F_{(3,20)}=7.61 ; p<0.05 ; 8 \mathrm{dpl}$ : Dunnett a priori comparison, $p<0.001$; Omnibus $F$ test, $\left.F_{(3,24)}=13.02 ; p<0.05\right)$. Both the amplitude and slope analyses indicated that the priming lesion itself did not enhance CTD synaptic efficacy.

Relative to the intact control animals, the maximum slope obtained after CTD stimulation significantly increased in the sprouted pathway after progressive lesions as early as $4 \mathrm{~d}$ after the IOI (Fig. 1; Dunnett a priori comparison, $p<0.02$; Omnibus $F$ test: $\left.F_{(3,22)}=4.26 ; p<0.05\right)$. Similarly, the progressive lesion group was the only group to differ significantly from the control group at the 6 and $8 \mathrm{~d}$ time points $(6 \mathrm{dpl}$ : Dunnett a priori comparison, $p<0.02$; Omnibus $F$ test, $F_{(3,20)}=3.22 ; p<0.05 ; 8$ dpl: Dunnett a priori comparison, $p<0.006$; Omnibus $F$ test, $\left.F_{(3,24)}=6.57 ; p<0.05\right)$.

We used three physiological criteria to verify the dentate responses to CTD stimulation: (1) the latency of response had to be $\sim 2.5 \mathrm{msec}$ after onset of stimulus artifact; (2) the EPSP had to follow $100 \mathrm{~Hz}$ stimulation of the angular bundle; and (3) the evoked population EPSPs had to reverse. The latency of response was indeed $\sim 2.5 \mathrm{msec}$ (Fig. 2). The evoked population EPSP for the animal with a one-stage entorhinal lesion illustrated in Figure 2 was maintained even when stimulated at a frequency of $100 \mathrm{~Hz}$ (Fig. 3). Similarly, the evoked response in the progressive lesion case (see Fig. 2) was maintained at a frequency of $100 \mathrm{~Hz}$ (Fig. 3). Finally, the responses for the progressive lesion case and the one-stage case illustrated in Figure 2 reversed with an onset of 2.5 msec after stimulus artifact onset (Fig. 3). The results from the $100 \mathrm{~Hz}$ tests were consistent with the report of Lomø (1971).

\section{Histology}

The extent of the lesions for the one-stage group and the progressive lesion group was found to be equivalent (Fig. 4). The medial and lateral EC were lesioned extensively, particularly layers II and III, the origin of the inputs to the dentate gyrus and hippocampus proper (Steward and Scoville, 1976; Steward and Vinsant, 1978). The presubiculum and parasubiculum were injured to some extent in all cases subjected to one-stage or progressive EC lesions. The priming lesions were restricted to the lateral-most aspect of the entorhinal area in all priming cases.

\section{DISCUSSION}

We show here that progressive unilateral cortical injury enhances the synaptic efficacy of efferents emerging from the contralateral 

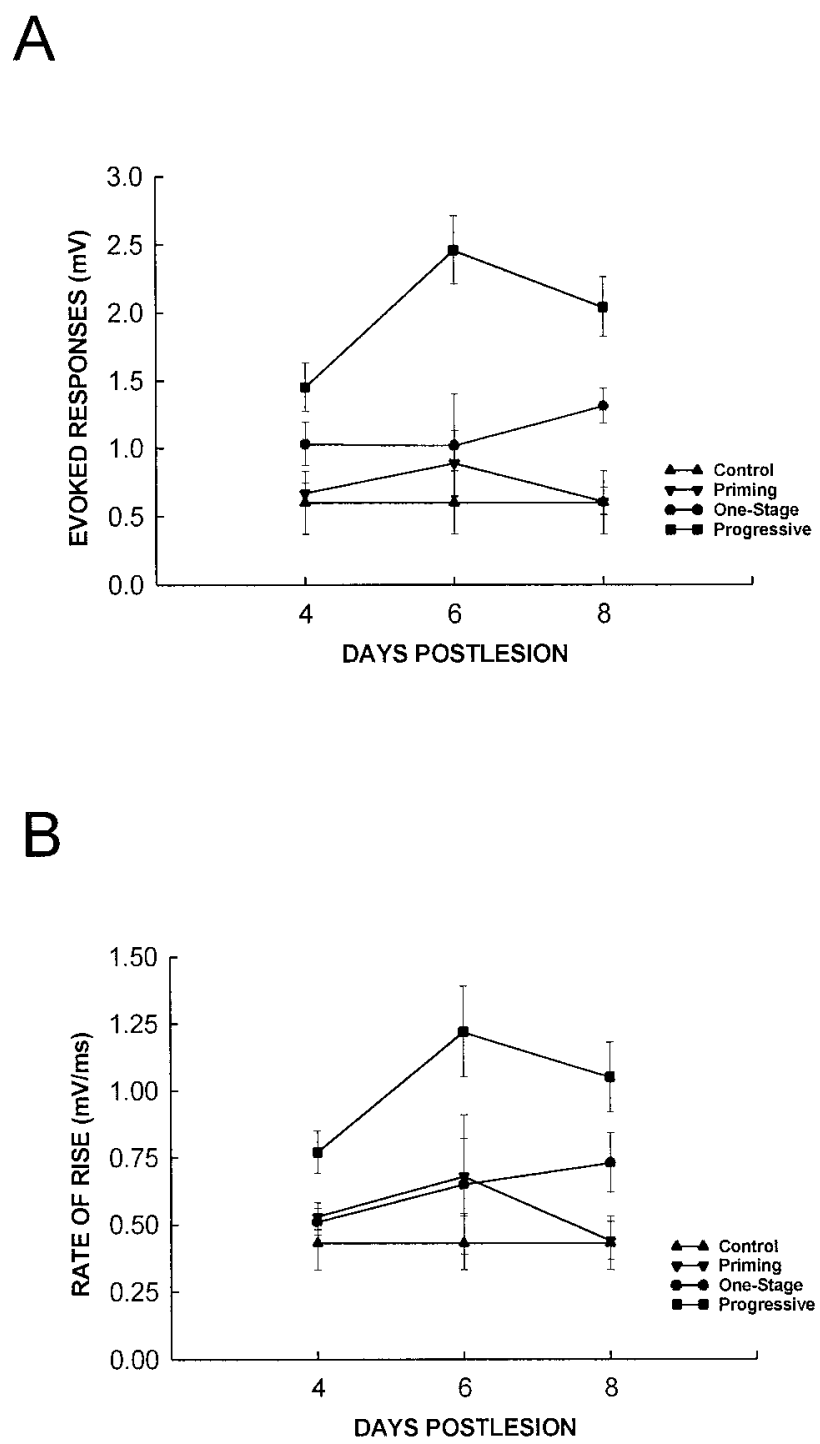

Figure 1. Analysis of evoked potentials after entorhinal lesions. At each of the time points, the progressive lesion group was the only group significantly different from the intact control group $(p<0.02)$ for both amplitude $(A)$ and slope $(B)$. The priming lesion itself did not significantly enhance synaptic efficacy relative to the intact controls. Although the synaptic drive of the one-stage group was elevated by the $8 \mathrm{~d}$ time point, the group was still not significantly greater than the control group.

homolog of the damaged cortical area. Progressive entorhinal lesions increased CTD synaptic efficacy as early as $4 \mathrm{dpl}$ and maintained a significantly elevated level of drive relative to controls throughout the period we examined. Although the synaptic efficacy of the one-stage group increased during this time interval, the group still did not differ significantly from the control animals by $8 \mathrm{dpl}$. We previously demonstrated that a unilateral two-stage lesion of the entorhinal area both enhanced the rate of CTD terminal proliferation and spared spatial memory function in rats (Ramirez et al., 1996). Whereas neither priming lesions alone nor one-stage unilateral EC lesions produced significant CTD sprouting 4 or $6 \mathrm{dpl}$, progressive lesions dramatically increased terminal proliferation as early as $4 \mathrm{~d}$ after the progressive lesion. Relative to rats with unilateral one-stage EC lesions, rats sustaining unilateral progressive lesions of the entorhinal area
A

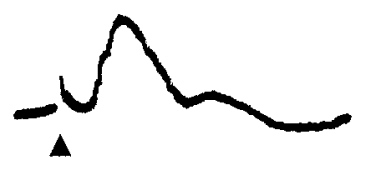

B
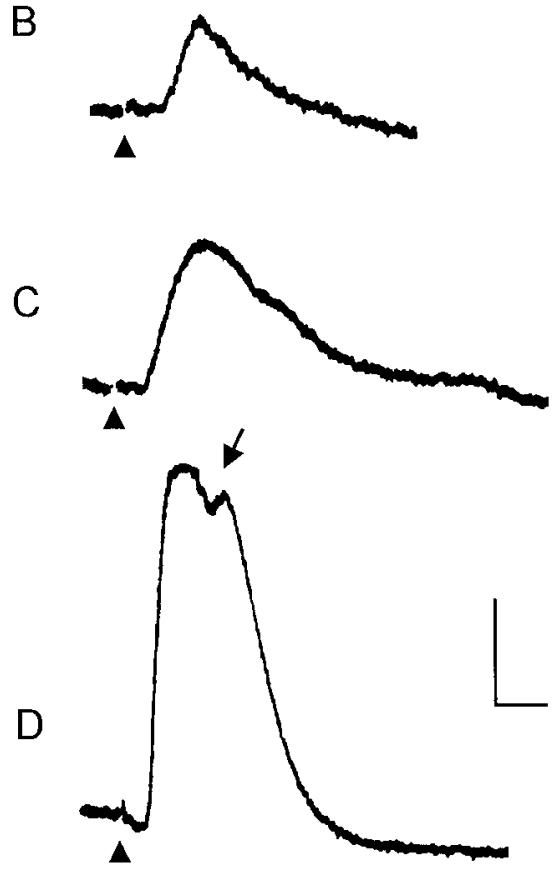

Figure 2. Examples of wave tracings from four experiments at the $6 \mathrm{~d}$ time point. $A, B$, Tracings from an intact rat and a rat with a priming lesion, respectively; note the similarity of the two tracings. $C$, Response from an animal with a one-stage lesion. $D$, Evoked response from a rat with a progressive lesion; note the dramatic increase in amplitude and the granule cell population spike (arrow), which were not observed in onestage cases at this time point. The arrowhead indicates the stimulus onset followed by a response $\sim 2.5 \mathrm{msec}$ later. Calibration: $1 \mathrm{mV}, 5 \mathrm{msec}$.

were not impaired in the retention of a learned alternation task; however, if the CTD was transected, the animals exhibited persistent spatial memory deficits. Because the increases in terminal proliferation we reported earlier may not necessarily enhance synaptic efficacy, the demonstration of an electrophysiological alteration after progressive lesions was an important step in determining the functional significance of the new terminals.

One interpretation of our results is that the priming lesion elicited a sprouting response, which itself was responsible for the enhanced synaptic efficacy after the secondary lesion. Our results argue against this interpretation, however, because the priming lesion group failed to exhibit enhanced synaptic efficacy despite survival periods after the priming lesion that were equivalent to those of the progressive lesion group. Our previous anatomical investigation in fact confirmed that the priming lesion itself did not initiate a substantial sprouting response as measured autoradiographically in the absence of the secondary lesion (Ramirez et al., 1996).

The most striking feature of our anatomical, electrophysiological, and behavioral data is the temporal concordance of the terminal proliferation, synaptic efficacy, and behavioral recovery. The progressive injury to the entorhinal area results in increased 
A<smiles></smiles>

B
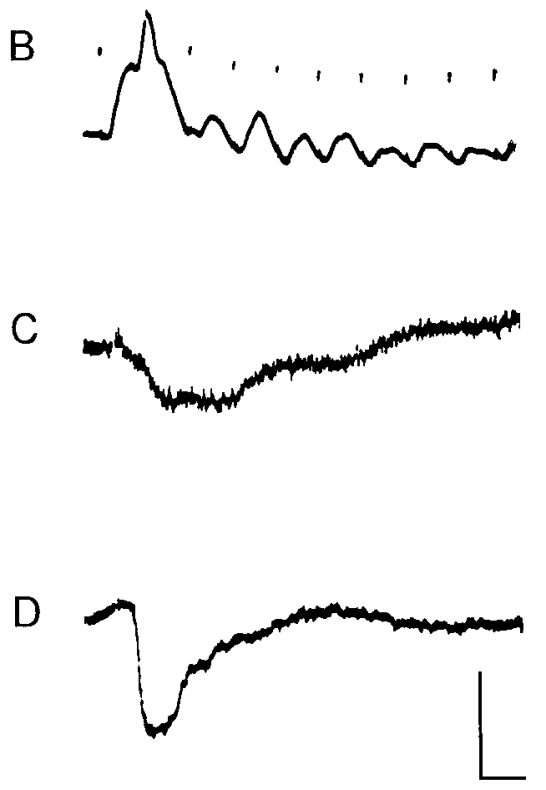

Figure 3. Examples of wave tracings confirming CTD stimulation of granule cells. One hundred hertz stimulation of one-stage case $(A)$ and a progressive lesion case $(B)$ illustrated in Figure 2 was accompanied by population EPSPs. Reversal of the response was observed in both the one-stage case $(C)$ and the progressive lesion case $(D)$ depicted in Figure 2 and in $A$ and $B$. Calibration: $A, 0.5 \mathrm{mV}, 10 \mathrm{msec} ; B, 2.0 \mathrm{mV}, 10 \mathrm{msec} ; C$, $D, 1.0 \mathrm{mV}, 5 \mathrm{msec}$.

and parallel rates for each of these postlesion changes. Our present findings are consistent with the hypothesis that progressive lesions accelerate CTD sprouting. Indeed, based on our anatomical, behavioral, and electrophysiological data, we propose that progressive entorhinal lesions accelerate the formation of functional CTD connections that are behaviorally meaningful and ameliorative.

Our findings support the possibility that axonal sprouting contributes to two important and potentially interrelated phenomena: functional reorganization after CNS injury and the "serial lesion effect." Vicarious substitution, a major hypothesis proposed to account for recovery of function after CNS injury, postulates that intact areas take over the function of the injured structures (Stein, 1998). Under the conditions explored in our studies as well as related studies (Loesche and Steward, 1977; Reeves and Smith, 1987), the intact contralateral homolog of the injured cortex appears capable of supporting the lost functions occurring as a consequence of unilateral brain damage by virtue of lesion-induced axonal sprouting. Both current source density analysis (Clusmann et al., 1994) and 2-deoxyglucose metabolic assessment (Beck et al., 1996) of the reinnervated dentate gyrus raise the possibility that the reorganization fails to completely restore the dentate gyrus to normal electrophysiological and metabolic functioning, however. Despite these functional shortcomings, when taken together with our previous findings the
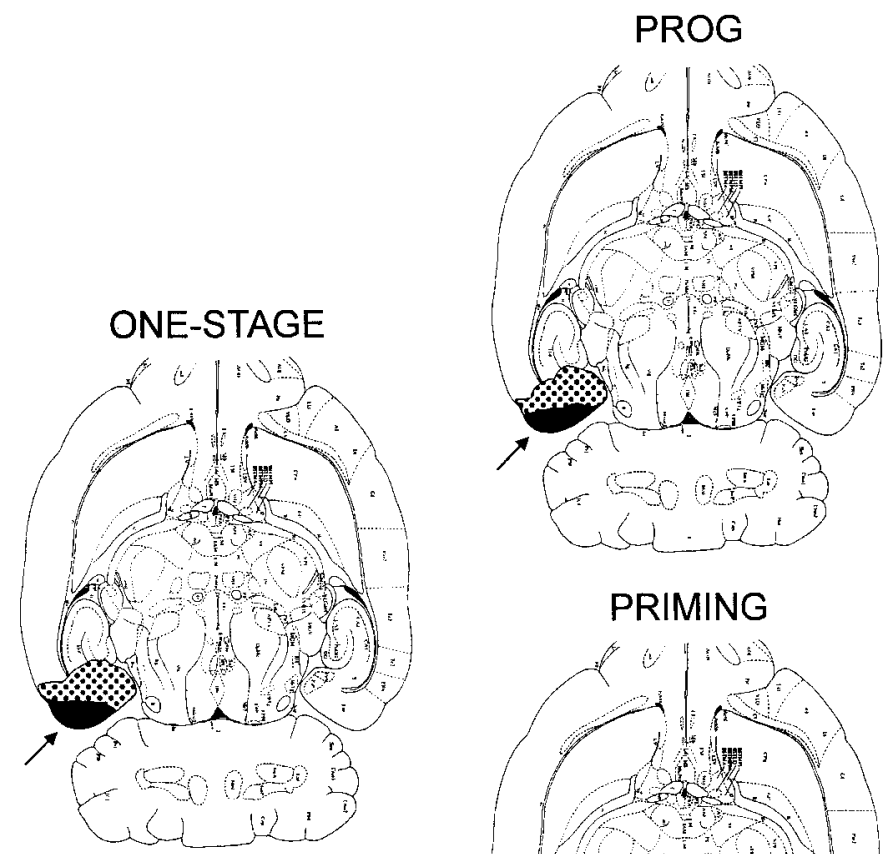

\section{BREGMA -6.1}

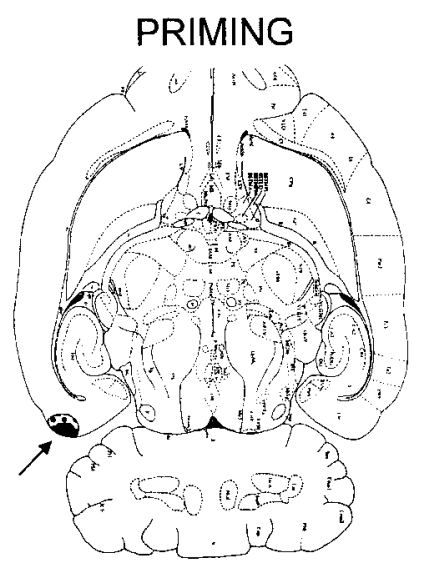

Figure 4. Minimum and maximum extent of entorhinal lesions. As the examples of the lesion reconstructions indicate (bregma at -6.1 in horizontal sections from Paxinos and Watson, 1986), the entorhinal damage for both the one-stage group and the progressive $(P R O G)$ lesion group was extensive. The priming lesions were small and restricted to the lateral-most entorhinal area. The stippled areas indicate the largest lesions; the black areas indicate the smallest lesions.

present results show that the reorganized hippocampal formation regains a functional physiological capacity that enables it to ameliorate the consequences of memory impairments associated with cortical injury and hippocampal deafferentation. Our present findings corroborate and extend previous reports (see Ramirez, 1997) that the increased synaptic efficacy of the CTD after a one-stage entorhinal lesion may be a key factor in the recovery of memory function.

For more than the last 150 years it has been known that slow-growing lesions of the CNS may produce mild neurological deficits despite extensive lesions of critical brain structures (Ramirez, 1997). The surgical preparation (the seriatum technique) developed to model slow-growing, or progressive, lesions involves making two lesions with an interlesion interval of between 7 and $30 \mathrm{~d}$. The seriatum technique results in minimal behavioral impairments after injury to a host of structures, including the mesial tegmentum of the rostral midbrain (Adametz, 1959), the superior colliculus (Weinberg and Stein, 1978), the frontal cortex (Stein et al., 1969), and the hippocampus (Stein et al., 1969).

The mechanism(s) responsible for the spared behavior or enhanced recovery of function after serial lesions has been enig- 
matic, although vicarious substitution and axonal sprouting have often been invoked as candidates. The enhanced rate of cortical reorganization observed after progressive entorhinal lesions (Scheff et al., 1977; Ramirez et al., 1996) and the consequent spared memory function (Ramirez et al., 1996) support the possibility that the acceleration of sprouting may contribute to the serial lesion effect. Our present results indicate that accelerated axonal sprouting after progressive entorhinal lesions is electrophysiologically significant and thereby strongly support the notion that enhanced CNS reorganization after serial lesions may underlie the serial lesion effect.

Vis-à-vis our findings, one feature of the serial lesion effect should be considered. The serial lesion phenomenon typically involves bilateral removal of a region in two stages; alternatively, we have removed the EC unilaterally. In principle, our findings indicate that progressive brain lesions may enhance the formation of functional synaptic contacts in the target of the damaged structure by a remaining intact input. The optimal conditions for behavioral sparing or an enhanced recovery of function would in all likelihood include sprouting by the injured structure's intact efferent projections. Although less than optimal perhaps, it is conceivable that compensation for bilateral serial lesions of a structure might involve enhanced sprouting of heterologous inputs to its deafferented target(s).

The cellular and molecular mechanisms responsible for accelerating sprouting after a progressive lesion are unclear. Recent observations in the dentate gyrus have indicated that entorhinal lesions increase mRNA levels and immunocytochemical label for growth factors such as basic fibroblast growth factor (GomezPinilla et al., 1992; Fagan et al., 1997), ciliary neurotrophic factor (Guthrie et al., 1997), insulin-like growth factor-1 (Guthrie et al., 1995), nerve growth factor, and brain-derived neurotrophic factor (Gwag et al., 1994). Indeed, intravenous infusion of basic fibroblast growth factor enhances the sprouting response of the acetylcholinesterase-containing septodentate projection to the outer molecular layer of the dentate gyrus after a one-stage unilateral EC lesion (Ramirez et al., 1999). The possibility exists that the priming lesion used in the present study prepares the genetic machinery of glia and/or neurons for the synthesis of these and related factors and thereby enhances the rate at which they are released after a progressive lesion. Certainly, understanding the cellular and molecular responses to CNS injury such as progressive lesions will provide the basis for developing future therapeutic strategies to ameliorate the effects of CNS injury. Elucidating the relation between CNS reorganization and functional outcome will continue to be of paramount importance, however, to determine the specific conditions wherein lesioninduced synaptic remodeling might be ameliorative, benign, or maladaptive.

\section{REFERENCES}

Adametz JH (1959) Role of recovery of functioning in cats with rostral reticular lesions. J Neurosurg 16:85-98.

Beck T, Weber M, Horvath E, Wree A (1996) Functional cerebral activity during regeneration from entorhinal lesions in the rat. J Cereb Blood Flow Metab 16:342-352.

Clusmann H, Nitsch R, Heinemann U (1994) Long lasting functional alterations in the rat dentate gyrus following entorhinal cortex lesion: a current source density analysis. Neuroscience 61:805-815.

Davis L, Vinsant SL, Steward O (1988) Ultrastructural characterization of the synapses of the crossed temporodentate pathway in rats. J Comp Neurol 267:190-202.

Fagan AM, Suhr ST, Lucidi-Phillipi CA, Peterson DA, Holtzman DM, Gage FH (1997) Endogenous FGF-2 is important for cholinergic sprouting in the denervated hippocampus. J Neurosci 17:2499-2511.

Freund H-J, Sabel BA, Witte OW (1997) Brain plasticity, advances in neurology, Vol 73. Philadelphia: Lippincott.

Goldowitz D, White WF, Steward O, Lynch G, Cotman C (1975) Anatomical evidence for a projection from the entorhinal cortex to the contralateral dentate gyrus of the rat. Exp Neurol 47:433-441.

Gomez-Pinilla F, Lee JW, Cotman CW (1992) Basic FGF in adult rat brain: cellular distribution and response to entorhinal lesion and fimbria-fornix transection. J Neurosci 12:345-355.

Guthrie KM, Nguyen T, Gall CM (1995) Insulin-like growth factor-1 mRNA is increased in deafferented hippocampus: spatiotemporal correspondence of a trophic event with axon sprouting. J Comp Neurol 352:147-160.

Guthrie KM, Woods AG, Nguyen T, Gall CM (1997) Astroglial ciliary neurotrophic factor mRNA expression is increased in fields of axonal sprouting in deafferented hippocampus. J Comp Neurol 386:137-148.

Gwag BJ, Sessler F, Kimmerer K, Springer JE (1994) Neurotrophic factor mRNA expression in dentate gyrus is increased following angular bundle transection. Brain Res 647:23-29.

Harris EW, Lasher SS, Steward O (1978) Habituation-like decrements in transmission along the normal and lesion-induced temporodentate pathways in the rat. Brain Res 151:623-631.

Hjorth-Simonsen A, Jeune B (1972) Origin and termination of the hippocampal perforant path in the rat studied by silver impregnation. J Comp Neurol 144:215-232.

Loesche J, Steward O (1977) Behavioral correlates of denervation and reinnervation of the hippocampal formation of the rat: recovery of alternation performance following unilateral entorhinal cortex lesions. Brain Res Bull 2:31-39.

Lomø T (1971) Patterns of activation in a monosynaptic cortical pathway: the perforant path input to the dentate area of the hippocampal formation. Exp Brain Res 12:18-45.

Paxinos G, Watson C (1986) The rat brain in stereotaxic coordinates. New York: Academic.

Ramirez JJ (1997) The functional significance of lesion-induced plasticity of the hippocampal formation. In: Brain plasticity, advances in neurology, Vol 73 (Freund H-J, Sabel BA, Witte OW, eds), pp 61-82. Philadelphia: Lippincott.

Ramirez JJ, McQuilkin M, Carrigan T, MacDonald K, Kelley MS (1996) Progressive entorhinal cortex lesions accelerate hippocampal sprouting and spare spatial memory in rats. Proc Natl Acad Sci USA 93:15512-15517.

Ramirez JJ, Finklestein SP, Keller J, Abrams W, George MN, Parakh T (1999) Basic fibroblast growth factor enhances axonal sprouting after cortical injury in rats. NeuroReport 10:1201-1204.

Reeves TM, Smith DC (1987) Reinnervation of the dentate gyrus and recovery of alternation behavior following entorhinal cortex lesions. Behav Neurosci 101:179-186.

Reeves TM, Steward O (1986) Emergence of the capacity for LTP during reinnervation of the dentate gyrus: evidence that abnormally shaped spines can mediate LTP. Exp Brain Res 65:167-175.

Scheff S, Benardo I, Cotman C (1977) Progressive brain damage accelerates axon sprouting in the adult rat. Science 197:795-797.

Squire LR (1992) Memory and the hippocampus: a synthesis from findings with rats, monkeys, and humans. Psychol Rev 99:195-231.

Stein DG (1998) Brain injury and theories of recovery. In: Restorative neurology: advances in pharmacotherapy for recovery after stroke (Goldstein LB, ed), pp 1-34. Armonk, NY: Futura.

Stein DG, Rosen JJ, Graziadie J, Mishkin D, Brink J (1969) Central nervous system: recovery of function. Science 166:528-530.

Steward O (1976) Reinnervation of dentate gyrus by homologous afferents following entorhinal cortical lesions in adult rats. Science 194:426-428.

Steward O, Scoville SA (1976) Cells of origin of entorhinal cortical afferents to the hippocampus and fascia dentata of the rat. J Comp Neurol 169:347-370.

Steward O, Vinsant SL (1978) Identification of the cells of origin of a central pathway which sprouts following lesions in mature rats. Brain Res 147:223-243. 
Steward O, Vinsant SL (1983) The process of reinnervation in the dentate gyrus of the adult rat: a quantitative electron microscopic analysis of terminal proliferation and reactive synaptogenesis. J Comp Neurol 214:370-386.

Steward O, Cotman CW, Lynch GS (1973) Re-establishment of electrophysiologically functional entorhinal cortical input to the dentate gyrus deafferented by ipsilateral entorhinal lesions: innervation by the contralateral entorhinal cortex. Exp Brain Res 18:396-414.

Steward O, Cotman C, Lynch G (1976a) A quantitative autoradiographic and electrophysiological study of the reinnervation of the dentate gyrus by the contralateral entorhinal cortex following ipsilateral entorhinal lesions. Brain Res 114:181-200.

Steward O, White WF, Cotman CW, Lynch G (1976b) Potentiation of excitatory synaptic transmission in the normal and in the reinnervated dentate gyrus of the rat. Exp Brain Res 26:423-441.

Steward O, Vinsant SL, Davis L (1988) The process of reinnervation in the dentate gyrus of adult rats: an ultrastructural study of changes in presynaptic terminals as a result of sprouting. J Comp Neurol 267:203-210.

Weinberg D, Stein DG (1978) Impairment and recovery of visual functions after bilateral lesions of the superior colliculus. Physiol Behav 20:323-329.

White WF, Goldowitz D, Lynch G, Cotman CW (1976) Electrophysiological analysis of the projection from the contralateral entorhinal cortex to the dentate gyrus in normal rats. Brain Res 114:201-209.

Wyss JM (1981) An autoradiographic study of the efferent connections of the entorhinal cortex in the rat. J Comp Neurol 199:495-512. 